\title{
Horizontes para una Matronería Comunitaria Tensiones y oportunidades para una praxis territorial
}

\author{
Horizons for a Community Midwifery \\ Tensions and opportunities for a territorial praxis
}

Gonzalo Infante-Grandón ${ }^{1}$, Augusto Obando-Cid ${ }^{2}$

\begin{abstract}
${ }^{1}$ Matrón; Departamento de Obstetricia y Ginecología; Departamento de Salud Pública. Facultad de Medicina, Universidad de La Frontera, Región de La Araucanía, Chile. ${ }^{2}$ Matrón; Departamento de Salud Pública. Facultad de Medicina, Universidad de La Frontera, Región de La Araucanía, Chile.
\end{abstract}

*Autor para correspondencia: gonzalo.infante@ufrontera.cl

RECIBIDO: 25 de Junio de 2020

APROBADO: 21 de Agosto de 2020

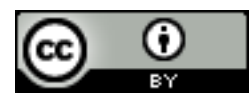

DOI: 10.22370/rev.mat.1.2020.2312

LOS AUTORES DECLARAN NO TENER CONFLICTO DE INTERESES

Palabras claves: Matronería; Asistencia Sanitaria; Salud Sexual; Salud Reproductiva; Salud Comunitaria. Key words: Midwifery; Delivery of Health Care; Sexual Health; Reproductive Health; Public Health.

\section{RESUMEN}

El presente ensayo propone un análisis crítico de la realidad de la Salud Sexual y Salud Reproductiva (SSySR) en el contexto de pandemia, en consideración de la priorización de ciertas acciones de salud y en desmedro de otras, que han generado la invisibilización de prestaciones y profesionales, lo que afecta -de forma particular- a las mujeres, familias y comunidades, en los ámbitos relacionados. Por ello, se plantea la necesidad de repensar lo comunitario como el intersticio superador -espacio de interacción y ocurrencia- del accionar de la matronería. Considerando estos argumentos, se esgrime como necesario superar falsos dilemas -entendidos como diferendos- para enfrentar la crisis socio-sanitaria, propiciando con ello la transformación de la disciplina en un agente social que participe de la conformación de una sociedad reconstruida y reconfigurada, en tanto pacto social.

\section{ABSTRACT}

This essay proposes a critical analysis regarding the reality of Sexual and Reproductive Health (SRH) in the pandemic context, considering the prioritization of certain health actions to the detriment of others; thus generating the invisibility of benefits and professionals, which affects -particularly- women, families and communities, in areas related to the SRH. For this reason, there is a need to rethink the community, as the overcoming gap - space for interaction and occurrence - of the actions of the Midwifery. Considering these arguments, wielded as necessary to overcome false dilemmas -understood as disagreements- to face the socio-sanitary crisis, thereby promoting the transformation of the discipline into a social agent, participating in the formation of a reconstructed and reconfigured society, according to a social pact. 


\section{INTRODUCCIÓN}

El 31 de diciembre de 2019 se notificó en Wuhan (China) el primer caso de coronavirus tipo 2 (1) causante del síndrome respiratorio agudo grave o SARSCoV-2 (mundialmente nominado como COVID-19). La infección provocada por el virus escaló vertiginosamente a una situación de pandemia, originando una crisis sanitaria de alcance global, con características de catástrofe. En Chile, el primer caso se notifica el día 3 de marzo del año 2020 (2), reconfigurando a partir de ese momento el quehacer de la asistencia sanitaria, que se orienta a los esfuerzos por atender la emergencia.

La reconfiguración excede los límites de la atención en salud, trastocando formas de organización económica, social y cultural. La invitación al confinamiento y distanciamiento social se concibe como una posibilidad para algunos(as) y se convierte en una quimera para otros(as). Las dialécticas vuelven a expresar tensiones permanentes: lo bueno y lo malo, lo central y lo periférico, lo urbano y lo rural, lo institucional y lo popular, lo individual y lo social, lo clínico y lo comunitario, dejando fuera de discusión lo necesario.

En el escenario nacional y global se expresan, de manera preeminente, estrategias orientadas a fortalecer la atención hospitalaria de alta complejidad tecnológica y se acuñan rótulos que definen a los equipos sanitarios de unidades intensivas como la primera línea de acción frente al virus, situando en ellos la responsabilidad de salir airosos frente a la crisis.

El Gobierno de Chile define un "Plan de Acción por Coronavirus" en el que la estrategia para enfrentarlo -coordinada por el Ministerio de Salud (MINSAL)- plantea el "fortalecimiento de la capacidad hospitalaria" (3). En el citado plan, no existe una declaración explícita respecto del quehacer de la Atención Primaria de Salud (APS). De hecho, el 25 de mayo, el subsecretario de Redes Asistenciales, Arturo Zúñiga, en la alocución que diariamente reporta el estado de situación por parte de las autoridades ministeriales, comunica la decisión de "convertir la Posta Central en el corazón de la batalla...en la Región Metropolitana" (4), refrendando el eje central de respuesta en el ámbito hospitalario.
El 3 de junio, el ministro de Salud Jaime Mañalich, atendiendo al insuficiente nivel de trazabilidad y seguimiento de casos y contactos, plantea un complemento y reorientación de la estrategia: "Se tomó la decisión de encargar a la Atención Primaria de Salud, dependiente de los municipios, el seguimiento activo de los casos y sus contactos y generar las alertas apropiadas para tener un aislamiento más efectivo" (5). Esto sugiere un nuevo escenario de integración entre niveles de atención (APS y Hospitalario), emergiendo interrogantes vinculadas a la gestión de los diferentes planes y programas de atención sanitaria, en particular todos aquellos No-COVID.

La propuesta de inclusión de la APS en el enfrentamiento de la pandemia, se convierte en el punto de acceso a lo comunitario, como axioma integrador que sugiere un espacio de síntesis e interlocución entre diferentes niveles y actores, proponiendo un horizonte de superación.

El presente ensayo propone un análisis crítico respecto de la realidad de la Salud Sexual y Salud Reproductiva (SSySR) en el contexto de pandemia, en consideración de la priorización de ciertas acciones de salud en desmedro de otras -que pasan a ocupar un lugar subalterno- con las consecuencias que esto produce en las personas que son destinatarias de sus prestaciones. Por lo tanto, el argumento es contrario a dialécticas de confrontación. Más bien, define a lo comunitario como el intersticio superador, en tanto espacio de ocurrencia del accionar de la matronería devenido en el ideario de encuentro para el abordaje de la SSySR.

En virtud de lo anterior, es de particular interés, la concurrencia de la matronería -como disciplinaen lo comunitario, dada su presencia extendida en los diferentes niveles y dispositivos de atención institucional de la salud en Chile, en particular lo concerniente a la asistencia sanitaria pública destinada a las mujeres y sus familias.

\section{REFLEXIÓN \\ SALUD SEXUAL Y SALUD REPRODUCTIVA EN TIEMPOS DE PANDEMIA}

La preocupación por la SSySR es permanente y puede ser entendida, en términos biopolíticos, como "la reproducción, las tasas de natalidad y mortalidad, el nivel de salud [y], la esperanza de vida se convierten 
en objeto de controles reguladores" (6). Esto implica, asumiendo la existencia de una sociedad de control (7), una serie de estrategias, metas y objetivos de desarrollo propuestos por agencias internacionales, los cuales son implementados -transversalmente- por las naciones del mundo. Los resultados obtenidos son periódicamente sometidos al escrutinio global, atendiendo a la diversidad de realidades contenidas al interior de los países, generando una clasificación acorde al éxito y cumplimiento mostrado.

Durante el desarrollo de la pandemia, diferentes actores institucionales y de la sociedad civil han manifestado preocupación, dando cuenta del impacto negativo que la crisis sanitaria ha tenido y podría provocar en la SSySR. En ese sentido, el Fondo de Población de Naciones Unidas (UNFPA) visualiza un socavamiento en la consecución de los Objetivos de Desarrollo Sostenible (ODS) (8), en tanto esta agenda busca "transformar nuestro mundo" para el año 2030 (9).

Los ODS 3 (Salud y Bienestar) y 5 (Igualdad de Género) tienen íntima relación con la SSySR, al definir a la planificación familiar, la eliminación de la violencia de género, la mutilación genital femenina y el matrimonio infantil como grandes áreas de preocupación (8). Por lo tanto, si el confinamiento y los efectos del virus se extienden más allá de 6 meses, se estima que las repercusiones del COVID-19 impactarían en 114 países de ingresos bajos y medianos y afectarían a unas 47 millones de mujeres que tendrían necesidades insatisfechas en el acceso a métodos anticonceptivos modernos, lo que generaría, como resultado, alrededor de 7 millones de embarazos no deseados (8). En ese mismo período, se avizora un incremento de 31 millones de casos de violencia de género, fundamentalmente la ejercida por la pareja en contextos domésticos (8).

En Chile, desde las subsecretarías y divisiones dependientes del MINSAL han emanado diferentes orientaciones y recomendaciones, tendientes a priorizar acciones sanitarias. En este sentido, la atención de gestantes, puérperas y/o díadas se concibe como ineludible y trascendental (10) en un escenario en el que los ingresos a control prenatal se recomiendan desde las 20 semanas, situación distinta al ingreso precoz desarrollado habitualmente en la APS del país. Por otro lado, se recomienda priorizar, en términos de suspensión de acciones, los controles de regula- ción de la fecundidad, dando lugar a prestaciones puntuales siempre que la protección anticonceptiva -que proporcionan los métodos- pueda verse en riesgo de disminución (11). Así, se asume, de manera tácita, que acciones de corte preventivo y promocional, como consultas y controles preconcepcionales o talleres educativos prenatales, son labores que pueden ser pospuestas en el escenario pandémico, fortaleciendo la preeminencia de lo curativo.

En virtud de lo anterior, usuarias de los servicios de salud, profesionales de la matronería y especialistas del ámbito gineco-obstétrico, han advertido la inexistencia de protocolos para la atención de SSySR en el escenario de pandemia (12). Además, investigaciones relacionadas con el parto y nacimiento han dado cuenta de la fragilidad de los sistemas de salud para sostener los avances alcanzados en la humanización de los nacimientos, determinando que el COVID-19 es un factor de riesgo para la violencia obstétrica (13).

Si bien después del terremoto que sacudió al país en 2010 las normas sobre regulación de la fecundidad incluyen un capítulo que aborda el quehacer en situaciones de emergencias y desastres (14), la realidad actual y los escenarios futuros con relación al COVID-19 no son alentadores: El aumento de los embarazos no deseados -en particular en mujeres adolescentes-, el incremento en las tasas de infecciones de transmisión sexual (ITS), la violencia sexual, la dificultad para acceder a métodos anticonceptivos y la violencia obstétrica, entre otras situaciones de vulneración de los Derechos Sexuales y Reproductivos, son una preocupación concreta (12). Asimismo, estos ocasionan efectos que se expresan, con mayor intensidad, en comunidades de mayor vulnerabilidad social y material, dando cuenta de la inequidad profunda que afecta históricamente al país (15).

En cuanto a la vinculación comunitaria, desde las directrices institucionales se esgrime como necesaria la generación de estrategias para la difusión de información activa hacia la población (11), sin que las orientaciones releven la importancia de un trabajo colaborativo y propositivo. Además, los actores sociales son considerados sujetos pasivos en el ámbito sanitario institucional.

De esta manera, se alude a la acción intersectorial en tanto se puedan identificar espacios comunitarios que permitan la instalación eventual de algunos 
servicios (11). Por este motivo, en el contexto de pandemia, se replica la lógica de la razón instrumental en la relación de las instituciones con los territorios, devolviendo y programando respuestas sin que en forma previa se planteen preguntas (16), a modo de diálogo entre saberes.

\section{LO CLÍNICO Y LO COMUNITARIO: DILEMA NO DIALÉCTICO}

En el primer extremo de este dilema ubicamos a lo individual dentro de la salud, lo cual apela a todos los aspectos relacionados con la atención del sujeto y a todo el accionar que se proyecta como el fundamento de la práctica médica y de las demás disciplinas de la salud. Esto debe ser entendido en términos conceptuales como "la clínica" (17)(18). Estas acciones sobre el sujeto individual han tenido profundas transformaciones, por lo cual se esgrime como necesaria la revisión de dichas prácticas de salud relacionadas con la atención, el diagnóstico y la curación del individuo.

De lo anterior, este cuerpo, superficie viviente en la que se inscribía la enfermedad, se ha complejizado drásticamente desde mediados del Siglo XX, dejando de ser entendido como una entidad monolítica, lo que ha llevado a generar nuevos y complejos niveles de observación/saber (18). Así, este cuerpo fue transformándose, paulatinamente, en organismo (17) y dado estos nuevos niveles de observación/saber fue por tanto necesaria la formación de un nuevo campo de conocimiento, instituyéndose así la biomedicina $(19,20)$.

Esta última comparte con la práctica clínica la atención/observación sobre el individuo y su cuerpo, dando paso en su observación/saber a la aparición de los sistemas, órganos, tejidos y en ultima instancia, moléculas. Por ello, la salud individual -en la actualidad- ha devenido en un afán microscópico y molecular, dado paso así a complejas tecnologías para representarle, abarcarle, diagnosticarle y tratarle.

Ahora bien, en el otro extremo del dilema podríamos ubicar a lo comunitario, un espacio de observación/saber en el que lo individual transita hacia el conjunto de individuos. Sin embargo, más que una sumatoria de individuos, este aspecto se debe entender dentro de la complejidad de lo social y de sus interacciones; hablamos por ello, de que el objeto en cuestión es la población (21). Desde esta perspectiva comunitaria/poblacional se articulan variados y complejos niveles de observación/saber para estas interacciones, las cuales son posibles de identificar como la familia y el barrio, hasta aquellas expresiones territorializadas entendidas como comunidad. Incluso, es posible agregar a esta escala otros espacios territoriales de interacción, como la ciudad y, también, los límites políticos-administrativos del territorio, en donde figuran las comunas, las regiones y -en última instancia- el Estado Nación.

Respecto del Estado Nación, era el objeto poblacional predilecto y el límite territorial de las interacciones sociales que estudiaba la ciencia de la Salud Pública. No obstante, la aparición de entidades supranacionales de salud, como la Organización Mundial de la Salud (OMS) y la Organización Panamericana de Salud (OPS), junto con el Reglamento Sanitario Internacional (RSI), propiciaron una reconfiguración tendiente a la desterritorialización.

En la actualidad -y desde las postrimerías del $\mathrm{Si}-$ glo XX-, dada la restructuración de la economía a escala global, se configuran espacios de interacción supranacionales en los que intervienen entidades económico-políticas desterritorializadas. A saber: la Unión Europea (UE), el Mercado Común del Sur (MERCOSUR), la Unión de Naciones Suramericanas (UNASUR) y la Organización del Tratado del Atlántico Norte (OTAN), por nombrar algunas.

Con ello, la ciencia de la Salud Pública se ha transformado, para tratar de abarcar, en última instancia, las interacciones que se dan en la globalidad y que incluyen al planeta entero.

La relación de observación/saber, a nivel poblacional, propició el nacimiento de la epidemiología como disciplina que estudia lo que ocurre sobre el pueblo. Su prefijo, en griego, tiene relación con la visita del médico al pueblo, con la mirada clínica al enfermo (22). Sin embargo, este prefijo fue suplantado por el de peste "loimos". Por ello, hasta hace poco se consideraba a la epidemiología como la disciplina que estudiaba las enfermedades, concepción que, en la actualidad, cambia por el estudio de los estados de la salud (23). 
Ahora bien, lo comunitario, que es el concepto central de la presente reflexión, se establece como lo en-común o el estar-en-común o el sentido-encomún (24) (25), aquello que dota de humanidad y de sentido a nuestra propia existencia, junto a la de otros y otras. Por ello, cuando discurrimos en torno a este nivel de interacción en salud se devela el límite en el cual individuo y población, como dos aporías abstractas, se intersectan y adquieren la forma de lo familiar, de lo común, de lo nuestro, de lo propio y de lo de todos y todas.

Por lo tanto, lo que se esgrimía como un dilema no es más que un diferendo que puede ser resuelto revisando las escalas y perspectivas que vinculan lo individual del sujeto con la globalidad del Estado Nación y los espacios supranacionales en salud. Es por tanto necesario tensionar los marcos interpretativos, dando cuenta de la historicidad de los procesos que permitieron la emergencia de cada nivel escalar y sin olvidar sus raíces, sean estas biológicas, psicológicas, sociales, culturales, políticas y económicas, en tanto les dieron forma y permitieron su estructuración.

\section{CONCLUSIÓN ELEMENTOS PARA UNA TEORÍA Y PRAXIS DE LA MATRONERÍA COMUNITARIA}

Para proponer una síntesis, podríamos iniciar esbozando una interrogante acerca de cuál es el objeto de la atención de la matronería, lo que se puede responder, en tanto se ha planteado, implícita y explícitamente, como un consenso que define como eje central y objeto de la matronería, la salud sexual, la salud reproductiva y la salud perinatal (26-28).

Ahora bien, una nueva interrogante sería: ¿cuál es el sujeto de la atención de la matronería? responderla da lugar a la emergencia de un dilema previamente abordado: ¿es el sujeto mujer? ¿ es el colectivo de mujeres? o ¿es la población?

Interpelando nuevamente a los niveles escalares nos propone esta falsa dicotomía y tensión entre individuo y espacios supranacionales; entre la biomedicina y la salud global.

En relación con lo previamente planteado, y en un esfuerzo de glocalidad (29), podríamos avizorar que el espacio escalar de interacción que deberíamos priorizar -desde la matronería- es lo comunitario, asumiendo que este lugar de intersección alberga la complejidad del sujeto individual devenido en lo molecular, como así también, el espacio políticoeconómico de lo supranacional. Lo comunitario es en tanto espacio material, simbólico e intersubjetivo (25) la interfaz que permite humanizar ambos extremos abstractos de la falsa dicotomía sujeto-globalidad, localizando toda abstracción y re-territorializando los flujos del mercado $(30,31)$, generando conocimientos parciales, contingentes y disputables (32-34), propiciando el devenir-con (35) otros y otras para construir juntos y juntas, lo que compartimos y tenemos en común $(24,25)$.

Es por ello que la matronería debe pensarse y reconstruirse de manera comunitaria, para reconfigurar al objeto y al sujeto de su atención, produciendocon (35) otros y otras conocimientos situados $(32,33)$ y estableciendo prácticas de salud re-territorializadas (36)(37) de cuidado-con y acompañamiento-con otras y otros, en ese espacio/interacción que nos es común, nos otorga un sentido-en-común y nos permite el estar-en-común (24) (25), que no es otro espacio/ interacción que lo comunitario.

Finalmente, es menester dejar en evidencia -dada la crisis de la SSySR ocasionada por la pandemia del COVID-19 a nivel global y local- que lo comunitario se erige como el espacio fundamental de intervención para dar respuesta a esta crisis sanitaria en el que la matronería es privilegiada, dada su vinculación y su interacción con este, tanto desde su nacimiento como disciplina, pero también en momentos de crisis social. Con ello se releva la importancia de lo domiciliario, del espacio íntimo de la familia y de las interacciones primarias y fundantes de lo social, para la renovación de las confianzas y la construcción de la salud de manera colectiva, en una praxis de rememoración que trae a la epidemiología de regreso, rescatando sus raíces fundacionales, abrigando esperanzas de superación de la crisis socio-sanitaria en tanto pacto social. Por lo tanto, es urgente que la matronería interactúe y se vincule -como agente social- al espacio germinal de una sociedad reconstruida y reconfigurada, incluyendo en su repertorio las prácticas y saberes tradicionales que dieron origen y cauce a su desarrollo. 


\section{REFERENCIAS}

1. Organización Mundial de la Salud. Nuevo coronavirus 2019 (COVID-19) [Internet]. OMS. 2020 [citado 6 de agosto de 2020]. p. 5. Disponible en: https://www.who.int/es/emergencies/diseases/novel-coronavirus-2019/advice-for-public

2. MINSAL. Ministerio de Salud confirma primer caso de coronavirus en Chile - Ministerio de Salud - Gobierno de Chile [Internet]. 2020 [citado 13 de junio de 2020]. p. 2. Disponible en: https://www. minsal.cl/ministerio-de-salud-confirma-primer-caso-de-coronavirus-en-chile/

3. Gobierno de Chile. Plan de Acción por $\mathrm{Co}^{-}$ ronavirus [Internet]. 2020 [citado 10 de agosto de 2020]. p. 2. Disponible en: https://www.gob.cl/coronavirus/plandeaccion/

4. Ministerio de Salud - Gobierno de Chile. ¡Todos juntos saldremos adelante! La ex Posta Central utiliza innovador tratamiento para manejo de pacientes con Covid-19 - División de Organizaciones Sociales [Internet]. 2020 [citado 10 de agosto de 2020]. p. 2. Disponible en: https://dos.gob.cl/todosjuntos-saldremos-adelante-la-ex-posta-central-utiliza-innovador-tratamiento-para-manejo-de-pacientes-con-covid-19/

5. Ministerio de Salud - Gobierno de Chile. Gobierno incorpora a la salud municipal en la trazabilidad de pacientes COVID-19 [Internet]. MINSAL. 2020. p. 4. Disponible en: https://www.minsal. cl/gobierno-incorpora-a-la-salud-municipal-en-latrazabilidad-de-pacientes-covid-19/

6. Byung-Chul Han. Psicopolítica: Neoliberalismo y nuevas técnicas de poder. 1a Edicion. Barcelona , España: Herder; 2014. 127 p.

7. Deleuze G. Post-scriptum sobre las sociedades de control [Internet]. Polis. Revista Latinoamericana. 2006 [citado 9 de julio de 2020]. p. 7. Disponible en: https://journals.openedition.org/polis/5509

8. Fondo de Población de Naciones Unidas (UNFPA); Repercusión de la pandemia de COVID-19 en la planificación familiar y la eliminación de la violencia de género, la mutilación genital femenina y el matrimonio infantil La pandemia representa un peligro para la consecución de los resultados transformadores [Internet]. UNFPA. 2020 [citado 20 de julio de 2020]. p. 1-8. Disponible en: https://www.unfpa. org/sites/default/files/resource-pdf/COVID-19_ impact_brief_for_UNFPA_23_April_2020_ES.pdf
9. NACIONES UNIDAS. La Agenda 2030 y los Objetivos de Desarrollo Sostenible: una oportunidad para América Latina y el Caribe [Internet]. Santiago, Chile; 2018 [citado 17 de junio de 2020]. p. 93. Disponible en: https://www.un.org/sustainabledevelopment/es/objetivos-de-desarrollo-sostenible

10. SUBSECRETARÍA DE SALUD PÚBLICA, SUBSECRETARÍA DE REDES ASISTENCIALES. ORIENTACIONES PARA EL MANEJO DE CASOS SARSCOV2 (COVID-19) EN GESTANTES, PUÉRPERAS Y/0 DÍADAS [Internet]. División de Prevención y Control de Enfermedades. Santiago, Chile; 2020 [citado 9 de agosto de 2020]. p. 32. Disponible en: https:// diprece.minsal.cl/wp-content/uploads/2020/07/ GESTANTES-PUÉRPERAS-Y-0-DiADAS.pdf

11. SUBSECRETARÍA DE REDES ASISTENCIALES DDAP. RECOMENDACIONES GENERALES PARA LA ORGANIZACIÓN DE LA ATENCIÓN EN ESTABLECIMIENTOS DE ATENCIÓN PRIMARIA DE SALUD EN CONTEXTO DE PANDEMIA SARS-CoV-2 [Internet]. División de Prevención y Control de Enfermedades. 2020 [citado 9 de agosto de 2020]. p. 14. Disponible en: https://diprece.minsal.cl/wp-content/ uploads/2020/03/RECOMENDACIONES-GENERALES-ESTABLECIMIENTOS-APS-V.6.pdf

12. APROFA. Chile sin acceso a salud reproductiva y sexual: encuesta de Miles denuncia preocupantes cifras [Internet]. 2020 [citado 10 de agosto de 2020]. p. 4. Disponible en: https://www.aprofa. cl/2020/05/19/chile-sin-acceso-a-salud-reproductiva-y-sexual-encuesta-de-miles-denuncia-preocupantes-cifras/

13. Sadler M, Leiva G, Olza I. COVID-19 as a risk factor for obstetric violence. Sex Reprod Heal Matters [Internet]. 1 de enero de 2020;28(1):1785379. Disponible en: https://www.tandfonline.com/doi/full/1 0.1080/26410397.2020.1785379

14. Ministerio de Salud - Gobierno de Chile. NORMAS NACIONALES SOBRE REGULACIÓN DE LA FERTILIDAD [Internet]. Santiago, Chile; 2018 [citado 2 de julio de 2020]. p. 252. Disponible en: https://www.minsal.cl/wp-content/ uploads/2015/09/2018.01.30_NORMAS-REGULACION-DE-LA-FERTILIDAD.pdf

15. Labra ME. La reinvención neoliberal de la inequidad en Chile: el caso de la salud. Cad Saude Publica [Internet]. agosto de 2002;18(4):104152. Disponible en: http://www.scielo.br/scielo. php?script=sci_arttextEpid=S0102-311X2002000400 010\&lng=es\&tlng=es 
16. Spinelli H. Volver a pensar en salud: programas y territorios. Salud Colect [Internet]. 24 de junio de 2016;12(2):149. Disponible en: http://revistas.unla. edu.ar/saludcolectiva/article/view/976

17. Canguilhem G. Escritos sobre la medicina. Buenos Aires: Amorrortu Editores; 2004. 128 p.

18. Foucault $\mathrm{M}$. El nacimiento de la clínica. Una arqueologia de la mirada médica. Buenos Aires: Siglo XXI Editores Argentina; 2008. 272 p.

19. Haraway D. Ciencia, cyborgs y mujeres La reinvención de la naturaleza. Madrid: Universitat de València: Ediciones Cátedra; 1995. 222 p.

20. Rose N. Políticas de la vida: biomedicina, poder y subjetividad en el siglo XXI. La Plata: UNIPE: Editorial Universitaria; 2012. 584 p.

21. Foucault M. Seguridad, territorio, población. Curso en el Collège de France (1977-1978). 1a Edición. Buenos Aires: Fondo de Cultura Economica; 2006. $484 \mathrm{p}$.

22. Pino LM, Hernández J. Los conceptos de peste y epidemia: semántica y lexicografía. Rev Filol y Lingüística. 2008;26:191-204.

23. Porta M. A Dictionary of Epidemiology. Oxford University Press; 2014. 376 p.

24. Esposito R. Communitas: origen y destino de la comunidad. Amorrortu; 2007. 214 p.

25. Nancy J-L. La comunidad inoperante. Lom Ediciones; 2000. 188 p.

26. Lillo E, Oyarzo S, Carroza J, Roman A. Midwifery in Chile - A Successful Experience to Improve Womeń s Sexual and Reproductive Health: Facilitators \& Challenges. J Asian Midwives [Internet]. 1 de junio de 2016 [citado 8 de junio de 2020];3(2):48-55. Disponible en: https://ecommons.aku.edu/jam/ vol3/iss1/7

27. Binfa L, Pantoja L, Gonzalez H, RansjöArvidson A-B, Robertson E. Chilean midwives and midwifery students' views of women's midlife health-care needs. Midwifery [Internet]. agosto de 2011;27(4):417-23. Disponible en: https://linkinghub. elsevier.com/retrieve/pii/S0266613810000288

28. Binfa L, Pantoja L, Ortiz J, Gurovich M, Cavada G, Foster J. Assessment of the implementation of the model of integrated and humanised midwifery health services in Chile. Midwifery [Internet]. abril de 2016;35:53-61. Disponible en: https://linkinghub. elsevier.com/retrieve/pii/S0266613816000383
29. Infante-Grandón G. GLOCALIZACIÓN, DEL EUFEMISMO GLOBAL A LA REALIDAD LOCAL. En: Solimano G, Ramírez J, editores. SALUD GLOBAL LOS RIESGOS PARA CHILE Y AMÉRICA LATINA. Santiago, Chile; 2018. p. 62-73.

30. Deleuze G, Guattari F. El anti-Edipo. Capitalismo y esquizofrenia. PAIDOS IBERICA; 1985. 428 p.

31. Deleuze G. Derrames. Entre el capitalismo y la esquizofrenia. 1a Edicion. Buenos Aires: Cactus; 2005. 384 p.

32. Haraway D. Ciencia, cyborgs y mujeres La reinvención de la naturaleza. Ediciones Cátedra; 1995.

33. Cruz MA, Reyes MJ, Cornejo M. Conocimiento Situado y el Problema de la Subjetividad del Investigador/a. Cinta de moebio [Internet]. diciem-

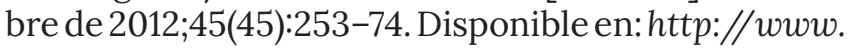
scielo.cl/scielo.php?script=sci_arttextEpid=S0717554X2012000300005Elng=enEnrm=isoEtlng=en

34. Haraway DJ. Testigo_Modesto@Segundo_ Milenio. HombreHembra_Conoce_Oncoratón : feminismo y tecnociencia. Cataluña, España: Editorial UOC; 2004. 360 p.

35. Haraway DJ. Staying with the trouble: making kin in the Chthulucene. Durham \& London: Duke University Press; 2016. 296 p.

36. Deleuze G, Guattari F. RIZOMA. 1aedicion. Valencia, España: Pre-Textos; 2010. 64 p.

37. Deleuze G, Guattari F. Mil mesetas. Capitalismo y esquizofrenia. 3a Edicion. Valencia, España: Pre-Textos; 2010. 522 p. 